\title{
Is HBV viral load at admission associated with development of acute-on-chronic liver failure in patients with acute decompensation of chronic hepatitis $B$ related cirrhosis?
}

\author{
Jian-Hua Lei", Feng Peng, Zi Chen and Xin-Qiang Xiao
}

\begin{abstract}
Background: Hepatitis B virus (HBV) reactivation is one of the most common precipitating events associated with acute decompensation (AD) or acute-on-chronic liver failure (ACLF) in chronic hepatitis B (CHB)-related cirrhotic patients. However, whether their serum HBV deoxyribonucleic acid (DNA) levels are associated with ACLF incidence and short-term mortality rate is still ambiguous.

Methods: The ACLF incidences, 28-day and 90-day liver transplantation (LT)-free mortality rates, previous nucleoside/nucleotide analogues (NUCs) treatments and serum HBV DNA levels at admission (ad-levels) of 111 hospitalized patients with AD of CHB-related cirrhosis were analyzed.

Results: 43 (38.7\%) patients developed ACLF. The 28-day and 90-day LT-free mortality rates of the ACLF cases were 15.4 and $40.9 \%$, respectively. Though NUCs inhibited HBV replication effectively, there were no differences in the ACLF incidence between antiviral treatment-naïve patients and NUCs treatment-experienced patients with or without interruptions $(37.5,41.7$ and $45.5 \%$, respectively, $P>0.05)$. The serum HBV DNA ad-level was similar between the patients with and without ACLF development (logarithms: $4.50 \pm 1.96$ vs $4.32 \pm 1.99 ; \geq 2000 \mathrm{IU} / \mathrm{ml}: 67.4 \%$ vs 67 . 6\%; both $P>0.05$ ), so was between the ACLF patients died or survived in 28 or 90 days (logarithms: $4.31 \pm 1.91$ vs 5 . $54 \pm 2.53,4.81 \pm 1.76$ vs $4.84 \pm 2.40$, respectively, both $P>0.05$ ).
\end{abstract}

Conclusion: Serum HBV DNA ad-level and previous NUCs treatment are not associated with incidence of ACLF and short-term mortality rate in the hospitalized patients with AD of CHB-related cirrhosis.

Keywords: Hepatitis B, chronic, Acute-on-chronic liver failure, Viral load, Nucleoside/nucleotide analogue

\section{Background}

Some compensated or decompensated cirrhotic patients might develop to a stage of acute-on-chronic liver failure (ACLF) characterized by hepatic and/or extrahepatic organ failures and high short-term mortality [1, 2]. In China, ACLF frequently occurs in patients with exacerbation of acute decompensation (AD) of chronic hepatitis B (CHB)-related cirrhosis [3-5].

\footnotetext{
* Correspondence: leijianhua@csu.edu.cn

Department of Infectious Diseases, the Second Xiangya Hospital, Central South University, No.139 Middle Renmin Road, Changsha, Hunan 410011,

People's Republic of China

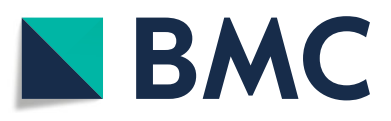

(c) The Author(s). 2019 Open Access This article is distributed under the terms of the Creative Commons Attribution 4.0 International License (http://creativecommons.org/licenses/by/4.0/), which permits unrestricted use, distribution, and reproduction in any medium, provided you give appropriate credit to the original author(s) and the source, provide a link to the Creative Commons license, and indicate if changes were made. The Creative Commons Public Domain Dedication waiver (http://creativecommons.org/publicdomain/zero/1.0/) applies to the data made available in this article, unless otherwise stated. patients is ambiguous $[3,4,11]$.
} virus (HBV) deoxyribonucleic acid (DNA) level and development of cirrhosis and hepatocellular carcinoma (HCC) in chronic HBV infected patients [6-8]. Control of $\mathrm{HBV}$ replication by nucleoside/nucleotide analogues (NUCs) therapies could reduce the risk of HCC and decompensated liver disease among CHB-related cirrhotic patients $[9,10]$. However, whether HBV DNA level is associated with incidence of ACLF and short-term mortality rate in acutely decompensated CHB-related cirrhotic 
As inhibiting replication of HBV in CHB-related cirrhotic patients by NUCs treatment is recommended by most authoritative guidelines [12-15], analysis on associations between NUCs treatment program, serum HBV DNA level, ACLF incidence and short-term mortality rate among hospitalized $\mathrm{CHB}$-related cirrhotic patients would be helpful to understand the role of NUCs therapies in treatment schemes and to formulate schemes to prevent the occurrence of ACLF.

\section{Methods}

\section{Patients and ethics approval}

111 patients with $\mathrm{AD}$ of CHB-related cirrhosis hospitalized in the infectious disease wards of the Second Xiangya Hospital, Central South University, during July and December 2016 were enrolled in the study. Data were obtained from the written medical records. The incidences of ACLF, 28-day and 90-day liver transplantation (LT)-free mortality rates, previous NUCs treatments and serum HBV DNA levels at admission (HBV DNA ad-levels) of the patients were analyzed.

The collection of the demographic data, clinical features and biological samples including serum, plasma and LT-resected liver tissue samples of the patients fulfilled the requirements of medical ethics. The ethical review committee of the hospital approved this study. Written informed consent was obtained from all participants.

\section{Diagnoses of $C H B$, liver cirrhosis and $A D$ events}

$\mathrm{CHB}$ was diagnosed according to the guidelines [12-15]. Patients with evidence of HCC or other chronic liver disease were excluded.

Liver cirrhosis was diagnosed by histological examination of the LT-resected liver, or FibroScan liver stiffness detected within 6 months more than 14.1 kilopascal together with Child-Turcotte-Pugh (CTP) scores more than 7 at admission, or imaging signs of nodular liver together with any two of the following criteria: the presence of ascites, hepatic encephalopathy, upper gastrointestinal bleeding, endoscopic detection of gastroesophageal varices, splenomegaly and peripheral blood platelet count below $100 \times 10^{9} / \mathrm{L}$ in the absence of other explanations [15-19].

$\mathrm{AD}$ events such as acute exacerbation of hepatic damage, overt ascites, upper gastrointestinal bleeding, hepatorenal syndrome and bacterial infection were defined according the clinical practice guidelines [20-22]. A model for end-stage liver disease (MELD) score assessing the severity of chronic liver injury was calculated in every patient on the first day of hospitalization according to the Malinchoc formula in which the levels of serum bilirubin, creatinine and international normalized ratio were analyzed simultaneously $[17,23]$.

\section{Diagnosis and grades of ACLF}

Diagnostic criteria and grades of ACLF were defined according to EASL-CLIF Consortium definition [1]. According to the consensus recommendations on ACLF of the Asian Pacific Association for the Study of the Liver (APASL) and studies of the domestic scholars [2-5, 2426], the current study defined the observation period of the incidence of ACLF development as 4 weeks following the onset of the $\mathrm{AD}$ events.

To evaluate the occurrence of organ failure or dysfunction in the patients, a retrospective analysis was performed every day in every patient by use of the CLIF-SOFA scale $[1,27]$. According to the scale, liver failure was defined by a serum bilirubin level of $\geq 204 \mu \mathrm{mol} / \mathrm{L}$, renal failure was defined by a serum creatinine level of $\geq 176 \mu \mathrm{mol} / \mathrm{L}$ or the need for renal replacement therapy, renal dysfunction was defined by a serum creatinine level between $132 \mu \mathrm{mol} / \mathrm{L}$ and $176 \mu \mathrm{mol} / \mathrm{L}$, cerebral failure was defined by grade III-IV hepatic encephalopathy, coagulation failure was defined by a INR $\geq 2.5$ or a platelet count of $\leq 20 \times 10^{9} / \mathrm{L}$, respiratory failure was defined by a ratio of partial pressure of arterial oxygen $(\mathrm{PaO} 2)$ to fraction of inspired oxygen (FiO2) of $\leq 200$ or an pulse oximetric saturation $(\mathrm{SpO} 2)$ to $\mathrm{FiO} 2$ ratio of $\leq 214$, circulatory failure was defined by a mean arterial pressure $<70 \mathrm{mmHg}$ despite adequate fluid resuscitation and vasoconstrictor requirements. Patients who had single kidney failure or single non-renal organ failure with presence of kidney dysfunction and/or grade I-II hepatic encephalopathy were diagnosed with ACLF grade 1. Patients who had two or more than two organ failures were diagnosed with ACLF grade 2 and ACLF grade 3 , respectively.

\section{Quantitatively detection of serum HBV DNA}

Quantitation of serum HBV DNA was assessed in StepOnePlus real-time polymerase chain reaction (PCR) system (Applied Biosystems Inc., USA), by using HBV DNA quantitative fluorescence diagnostic kit (Sansure biotech Inc. Ltd., China) [28]. The lower limit of the detection was $10 \mathrm{IU} / \mathrm{mL}$ and the linear range was from 20 $\mathrm{IU} / \mathrm{mL}$ to $2.0 \times 10^{9} \mathrm{IU} / \mathrm{mL}$.

\section{Statistical analysis}

All statistical analyses were performed with $\mathrm{IBM}^{\bullet} \mathrm{SPSS}^{\bullet}$ Statistics version 20.0, using descriptive statistical indexes such as mean, standard deviation (SD), range, median, mortality rate, constituent ratio, et al. Chi-squared test, Fisher's exact test, Analysis of Variance, LSD multiple comparisons tests and Kruskal-Wallis $\mathrm{H}$ test were performed for comparison of means or ratios. The homogeneity test of variance of the quantitative data was performed by Levene test. Binary logistic analyses of the 28-or 90-day mortality rates in patients without LT treatment were performed. The $P$ values in this paper were all derived from the double tailed tests and $\mathrm{P}$ value less than 0.05 was considered statistically significant. 


\section{Results}

Prevalence of ACLF and the 28-day and 90-day mortality rates

According to the EASL-CLIF diagnostic criteria, 3 patients were diagnosed with ACLF grade 1, 27 with ACLF grade 2 and 13 with ACLF grade 3 . The prevalence rate of ACLF was 38.7\%. 26 patients were diagnosed with ACLF at admission and 17 patients developed ACLF during hospitalization. The prevalence rates of liver failure $(54.9 \%)$ and coagulation failure $(32.4 \%)$ were significantly higher than the rates of cerebral failure (11.7\%), renal failure $(7.2 \%)$, circulatory failure $(6.3 \%)$ and respiratory failure $(3.6 \%)(P<0.05)$. The prevalence rates of renal and cerebral dysfunction were 5.4 and $3.6 \%$, respectively. Liver failure was observed in 21 (30.9\%) of the 68 patients without ACLF development while extrahepatic organ failure was rarely found.

The 28-day and 90-day LT-free mortality rates of the patients without ACLF development were both zero. One patient without extrahepatic organ failure developed liver failure and received LT treatment on the 55th day of hospitalization and recovered.

Detailed 28-day medical records were obtained in 42 of the 43 ACLF cases. 3 (7.1\%) underwent LT within 28 days and survived till the 90th day. 6 (15.4\%) of the rest 39 patients without LT treatment died before the 28th day. 8 (26.7\%) of the 30 cases with detailed 90-days medical records were treated with LT, one $(12.5 \%)$ of them died before the 90th day. 9 (40.9\%) of the rest 22 patients without LT treatment died before the 90th day.

None of the 3 cases diagnosed with ACLF grade 1 was treated with LT, one patient died within 28 days and another died during the 28th and the 90th day. The 28-day or 90-day LT-free mortality rates of the cases diagnosed with ACLF grade 2 were zero and 21.4\%, respectively. The 28-day or 90-day LT-free mortality rates of the cases diagnosed with ACLF grade 3 were 41.7 and 83.3\%, respectively.

\section{Gender and age distribution, MELD scores at admission}

Gender and age distributions were not significantly different in the patients with ACLF or without (constituent ratio of males: $90.7 \%$ vs $77.9 \%$; age: $47.4 \pm 11.2$ vs $47.6 \pm$ 11.4 years. Both $P>0.05)$. MELD scores at admission were significantly higher in the patients who developed ACLF than those did not $(26.6 \pm 5.4$ vs $14.2 \pm 7.4$, $P<0.05)$. Among the 85 patients who did not develop ACLF before admission, 17 patients developing ACLF during hospitalization had higher MELD scores (22.4 \pm 3.0 vs $14.2 \pm 7.4, P<0.05)$. MELD scores of the patients who developed ACLF after admission were lower than those who were diagnosed with ACLF at admission $(22.4 \pm 3.0$ vs $29.3 \pm 4.9, P<0.05)$.

\section{PEs associated with AD or ACLF}

Potential PEs associated with AD or ACLF were present in 56 cases $(50.5 \%)$. The most frequent PE was bacterial infection (19 cases, 17.1\%), followed by overwork (12 cases, 10.8\%), interruption/discontinuation of antiviral treatment (10 cases, 9\%), suspected drug-induced liver injury (6 cases, 5.4\%) and excessive alcohol consumption (5 cases, 4.5\%). 9 cases (8.1\%) had infrequent PEs like flu or cold (3 cases), acute HEV infection (2 cases), resistance to NUCs (2 cases), complicated hyperthyroidism (1 case) and use of immunosuppressive agents (1 case).

The ACLF incidence was not significantly different between the patients with or without presence of $\mathrm{PE}$ (41.9\% vs $34.7 \%, P>0.05$ ). 7 of the 13 patients who had PEs of NUCs resistance or interruption/discontinuation of antiviral treatment developed ACLF, but their ACLF incidence was not statistically different from the others' (53.9\% vs $36.7 \%, P>0.05$ ). However, only 2 of the 12 patients with overwork as PE developed ACLF, showing a lower ACLF incidence than the others (16.7\% vs $48.0 \%$, Fisher's exact test, $P=0.05)$.

\section{Incidence of ACLF in patients with different previous NUCs treatment experiences (Table 1)}

88 cases $(79.3 \%)$ were antiviral treatment-naïve, NUCs therapies were started in them when the symptoms of AD were obvious.87 of them were treated with entecavir (ETV) as soon as they were admitted to the hospital. One patient failed to receive NUCs treatment due to intestinal perforation and peritonitis.

Twelve patients $(10.8 \%)$ were previously treated with NUCs for long-terms (range from 14 to 286 weeks, median: 58 weeks) till their admissions to the hospital, without interruptions. The NUCs treatment schemes were persisted during their hospitalizations. 8 of them were treated with ETV, 2 with lamivudine (LAM), consistently. One patient was previously treated with ETV for 75 weeks and then sequentially treated with ETV and tenofovir disoproxil fumarate (TDF) due to a confirmed ETV resistance mutation. Another patient was previously treated with LAM for 1 year and then sequentially treated with ETV because of the worry about NUCs resistance.

11 patients $(9.9 \%)$ had been treated with NUCs previously for long-terms (range from 43 to 312 weeks, median: 104 weeks) and subsequently interrupted or discontinued the NUCs treatments till the occurrence of $\mathrm{AD}$ events. The interruption periods were range from 9 to 267 weeks, with a median as 26 weeks. 8 of them were previously treated with ETV, one with LAM and 2 with adefovir dipivoxil. ETV treatment was started after the day of admission in 10 of them. One patient was treated with TDF due to a confirmed ETV resistance mutation.

Table 1 indicated that previous NUCs treatment could effectively inhibit HBV replications and interruption/ 
Table 1 Incidence of ACLF in patients with different previous NUCs treatment experiences

\begin{tabular}{|c|c|c|c|c|c|c|c|c|}
\hline \multirow[t]{2}{*}{$\begin{array}{l}\text { NUCs } \\
\text { experiences }\end{array}$} & \multicolumn{2}{|c|}{$\begin{array}{l}\text { HBV DNA ad-level } \\
(\mathrm{IU} / \mathrm{ml}), \mathrm{n}(\%)\end{array}$} & \multirow[t]{2}{*}{$\begin{array}{l}\log (\mathrm{HBV} D N A) \\
\text { mean } \pm \mathrm{SD}\end{array}$} & \multirow[t]{2}{*}{$\begin{array}{l}\text { MELD scores, } \\
\text { mean } \pm \text { SD }\end{array}$} & \multicolumn{4}{|c|}{ ACLF development, n (\%) } \\
\hline & $<2000$ & $\geq 2000$ & & & $n$ & before admission & after admission & Total \\
\hline naïve & $26(29.5)$ & $62(70.5)$ & $4.55 \pm 1.71$ & $19.7 \pm 8.9$ & 88 & $22(25.0)$ & $11(12.5)$ & $33(37.5)$ \\
\hline maintained & $8(66.7)$ & $4(33.3)$ & $2.27 \pm 2.48$ & $17.5 \pm 9.9$ & 12 & $2(16.7)$ & $3(25.0)$ & $5(41.7)$ \\
\hline interrupted & $2(18.2)$ & $9(81.8)$ & $5.40 \pm 1.90$ & $15.4 \pm 8.8$ & 11 & $2(18.2)$ & $3(27.3)$ & $5(45.5)$ \\
\hline Total & $36(32.4)$ & $75(67.6)$ & $4.39 \pm 1.97$ & $19.0 \pm 9.0$ & 111 & $26(23.4)$ & $17(15.3)$ & $43(38.7)$ \\
\hline
\end{tabular}

1. NUCs experiences: naïve: antiviral treatment-naïve patients; maintained: patients with sustained long-term NUCs treatments till admission; interrupted: patients with interruption or discontinuation of antiviral treatment after long-term of NUCs therapies

2. HBV DNA ad-level $<2000 \mathrm{lU} / \mathrm{ml}$ or $\geq 2000 \mathrm{lU} / \mathrm{ml}$ : Fisher's exact test, $P=0.032$

3. Log(HBV DNA) (logarithm of the serum HBV DNA ad-level): $F=10.150, P=0.000$

4. MELD scores (MELD scores at admission): $F=1.301, P=0.276$

5. ACLF development: Fisher's exact test, $P=0.549$; ACLF vs No-ACLF: $X^{2}=0.309, P=0.828$; ACLF after admission vs No-ACLF: Fisher's exact test, $X^{2}=2.083$,

$P=0.353 ;$ ACLF before admission vs No-ACLF: Fisher's exact test, $P=1.000$

discontinuation of NUCs treatment might lead to viral relapse, but it did not influence the incidence of ACLF development $(P>0.05)$.

\section{Association between serum HBV DNA ad-level and incidence of ACLF or short-term mortality rate (Table 2, Table 3)}

Serum HBV DNA ad-levels did not significantly vary between the 43 cases who developed ACLF and the 68 cases who did not (all $P>0.05$ ). Respective analyses based on the data of the 26 cases diagnosed with ACLF at admission and 17 cases developed ACLF after admission got consistent conclusion with the previous analysis (all $P>0.05$ ) (Table 2). In the 39 ACLF cases with detailed 28-day medical records and without LT treatment, serum HBV DNA ad-levels of the 6 patients died in 28 days and the 33 patients survived till the 28th days were similar (logarithms: $4.31 \pm 1.91$ vs $5.54 \pm 2.53, P>0.05$ ). In the 22 ACLF cases with detailed 90-day medical records and without LT treatment, serum HBV DNA ad-levels of the 9 patients died in 90 days were not significantly different from that of those survived till the 90th days (logarithms: $4.81 \pm 1.76$ vs $4.84 \pm 2.40, \quad P>0.05$ ). The short-term LT-free mortality rates of ACLF patients with serum HBV DNA ad-levels lower than $2000 \mathrm{IU} / \mathrm{ml}$ or $2 \times 10^{6} \mathrm{IU} / \mathrm{ml}$ did not vary from those of higher (both $P>0.05$ ) (Table 3).

\section{Logistic analysis of the 28 - or $\mathbf{9 0 - d a y ~ m o r t a l i t y ~ r a t e s ~ i n ~}$ patients without LT treatment}

We performed a binary logistic analysis of the 28- or 90-day mortality rates in patients without LT treatment. The 28 or 90 days outcomes of the patients with or without ACLF development were set as dependent variables. Gender, age, ALT, MELD score and logarithm of the serum HBV DNA ad-level were set as covariates. 106 cases were involved in the 28-day analysis, and 55 cases were included in the 90-day analysis. The results showed that MELD score at admission, i.e. the degree of liver decompensation, was the main factor affecting the recent mortality of the patients (OR $=1.139$, OR95\% CI:1.0061.289, $P=0.040 ;$ OR $=1.259$, OR95\% CI:1.049-1.512, $P=$ 0.014 , respectively). The other factors, including HBV DNA ad-level, had not significant influences (all $P>0.05$ ).

\section{Discussion}

According to the EASL-CLIF diagnostic criteria, the CLIF-SOFA scores and the prevalence of ACLF in the 111 patients enrolled were consistent with the reports from Shanghai Municipality and Zhejiang Province, China $[3,5]$. Comparison of MELD scores at admission between the patients developing ACLF and those not, indicated that proper treatment scheme in the early stage of $\mathrm{AD}$ was vital to reduce ACLF incidence.

Table 2 Serum HBV DNA ad-levels of the patients who developed to ACLF or not

\begin{tabular}{|c|c|c|c|c|c|c|c|c|}
\hline \multirow[t]{2}{*}{ Groups } & \multirow[t]{2}{*}{$n$} & \multicolumn{6}{|c|}{ HBV DNA (IU/ml), n (\%) } & \multirow{2}{*}{$\begin{array}{l}\text { Log } \\
(H B V D N A), \\
\text { mean } \pm S D\end{array}$} \\
\hline & & $<10$ & $\geq 10$ & $<2000$ & $\geq 2000$ & $<2 \times 10^{6}$ & $\geq 2 \times 10^{6}$ & \\
\hline Non-ACLF & 68 & $4(5.9)$ & $64(94.1)$ & $22(32.4)$ & $46(67.6)$ & $56(82.4)$ & $12(17.6)$ & $4.32 \pm 1.99$ \\
\hline ACLF before admission & 26 & $1(3.80)$ & $25(96.2)$ & $7(26.9)$ & $19(73.1)$ & $20(76.9)$ & $6(23.1)$ & $4.65 \pm 1.99$ \\
\hline ACLF after admission & 17 & $0(0.0)$ & $17(100.0)$ & $7(41.2)$ & $10(58.8)$ & 15(88.2) & $2(11.8)$ & $4.27 \pm 1.94$ \\
\hline Total & 111 & $5(4.5)$ & $106(95.5)$ & $36(32.4)$ & 75 (67.6) & $91(82.0)$ & $20(18.0)$ & $4.39 \pm 1.97$ \\
\hline
\end{tabular}

1. Groups: Non-ACLF, patients without ACLF development; ACLF, patients with ACLF development;

2. $\mathrm{HBV}$ DNA $<10 \mathrm{IU} / \mathrm{ml}$ or $\geq 10 \mathrm{IU} / \mathrm{ml}$ : Fisher's exact test, $P=0.827$

3. HBV DNA $<2000 \mathrm{IU} / \mathrm{ml}$ or $\geq 2000 \mathrm{IU} / \mathrm{ml}^{\mathrm{N}} \mathrm{X}^{2}=0.953, P=0.597$

4. HBV DNA $<2 \times 10^{6} \mathrm{IU} / \mathrm{ml}$ or $\geq 2 \times 10^{6} \mathrm{IU} / \mathrm{ml}$ : Fisher's exact test, $P=0.643$

5. Log(HBV DNA) (logarithm of the serum HBV DNA ad-level): $F=0.304, P=0.739$ 
Table 3 The 28-day or 90-day LT-free mortality rates in the ACLF patients with serum HBV DNA ad-level lower or higher than $2000 \mathrm{IU} / \mathrm{ml}$ or $2 \times 10^{6} \mathrm{IU} / \mathrm{ml}$

\begin{tabular}{llllll}
\hline $\begin{array}{l}\text { HBV } \\
\text { DNA } \\
(\mathrm{IU} / \mathrm{ml})\end{array}$ & \multicolumn{2}{l}{ 28-day prognosis } & & \multicolumn{2}{c}{ 90-day prognosis } \\
& $\mathrm{n}$ & mortality, $\mathrm{n}(\%)$ & & $\mathrm{n}$ & mortality, $\mathrm{n}(\%)$ \\
\hline$<2000$ & 13 & $1(7.7)$ & & & $3(42.9)$ \\
$\geq 2000$ & 26 & $5(19.2)$ & 15 & $6(40.0)$ \\
$<2 \times 10^{6}$ & 31 & $4(12.9)$ & 17 & $7(41.2)$ \\
$\geq 2 \times 10^{6}$ & 8 & $2(25.0)$ & 5 & $2(40.0)$ \\
Total & 39 & $6(15.4)$ & 22 & $9(40.9)$ \\
\hline
\end{tabular}

1. LT: liver transplantation

2. HBV DNA $<2000 \mathrm{IU} / \mathrm{ml}$ or $\geq 2000 \mathrm{IU} / \mathrm{ml}: 28$-day LT-free mortality rates: Fisher's exact test, $P=0.643 ; 90$-day LT-free mortality rates: Fisher's exact test, $P=1.000$

3. HBV DNA $<2 \times 10^{6} \mathrm{IU} / \mathrm{ml}$ or $\geq 2 \times 10^{6} \mathrm{IU} / \mathrm{ml}: 28$-day LT-free mortality rates: Fisher's exact test, $P=0.583$; 90-day LT-free mortality rates: Fisher's exact test, $P=1.000$

However, there was no statistical correlation between previous NUCs treatment and ACLF incidence. It meant that, although continuous NUCs therapy could reduce the risk of $\mathrm{AD}$ event among cirrhotic patients [6-9], once AD occurred, the previous NUCs treatment would not interfere the ACLF development.

This assumption was also consistent with the analysis of PEs. Similar to other reports [1, 3-5], interruption/discontinuation of NUCs therapies was one of the frequent PEs associated with AD or ACLF in the 111 patients. HBV replication level was significantly higher in the patients with interruption/discontinuation of antiviral treatments, but there was no difference in the proportion of ACLF development among the antiviral treatment-naïve patients and the NUCs treatment-experienced patients with or without interruptions. According to the reports from Shanghai, China, patients with ACLF had been more frequently treated with NUCs within the 6 months prior to admission than patients with AD without ACLF [3]. It was interesting that ACLF incidence and short-term mortality rate of the patients without presence of PEs were also not related to the HBV DNA ad-level.

Obviously, ACLF incidence and short-term mortality rate were mainly dependent on the severity of systemic inflammation and the number of organ failures, not on the levels of HBV replication of the patients. Many evidences suggested that development of ACLF was associated with many factors such as abnormal immune reaction, imbalance of pro-inflammatory and anti-inflammatory cytokines, and so on $[29,30]$. So the urgent treatments in the hospitalized acutely decompensated CHB-related cirrhotic patients were reducing the inflammatory responses and maintaining the major organs such as liver and kidney so as to reduce ACLF development and decrease mortality rate.

However, NUCs treatment was still necessary for the hospitalized CHB-related cirrhotic patients [12-15]. The incidence of ACLF and short-term mortality rate in the acutely decompensated cirrhotic patients were different from the incidence of AD and HCC and long-term mortality rate in the cirrhotic patients. Effective anti-viral therapies would reduce the risk of $\mathrm{HCC}$ and decompensated liver disease among the cirrhotic patients [6-9]. Regression of fibrosis and even reversal of liver cirrhosis have been reported in patients with prolonged suppression of $\mathrm{HBV}$ replication [31]. Besides, NUCs treatments were well tolerated in acutely decompensated patients, without significant side effects $[9,10]$. As shown in the current study, the previous NUCs treatments of the 23 patients did not increase the incidence of ACLF or the short-term mortality rate. So, continuous NUCs treatments from the admission days were recommended in view of their long-term prognoses.

Although the cases recruited were limited and the dynamic changes of the HBV DNA levels around the occurrences of $\mathrm{AD}$ events were inavailable, the conclusion of the current study could still be credible. It was consistent with other data, although it was not the emphases of the other reports $[1,3-5]$. So, for the hospitalized patients with AD of CHB-related cirrhosis, besides NUCs treatment, physicians should pay more attention to other approaches to reduce ACLF incidence.

\section{Abbreviations \\ ACLF: acute-on-chronic liver failure; AD: acute decompensation; $\mathrm{CHB}$ : chronic hepatitis B; Cl: Confidence Intervals; CTP score: Child-Turcotte-Pugh (CTP) score; DNA: deoxyribonucleic acid; HBV DNA ad-level: serum HBV DNA levels at admission; HBV: hepatitis B virus; HCC: hepatocellular carcinoma; MELD score: a model for end-stage liver disease score; NUCs: nucleoside/nucleotide analogues; OR: odds ratio; PaO2: partial pressure of arterial oxygen; PCR: polymerase chain reaction; PE: precipitating event; PTA: prothrombin activity; SD: standard deviation; SpO2: pulse oximetric saturation}

\section{Acknowledgements}

Quantitatively detection of HBV seromarkers and serum HBV DNA levels were operated by doctor Xin-Qiang Xiao and Qian Zhou, the Institute of Liver Diseases, Central South University.

\section{Funding}

Design of the study and collection, analysis, and interpretation of data and the manuscript writing and publishing were funded by the Department of Infectious Diseases, the Second Xiangya Hospital, Central South University.

\section{Availability of data and materials}

The datasets analyzed during the current study are not publicly available due to protection of the patients' privacy, but are available from the corresponding author on reasonable request.

\section{Authors' contributions}

$J H L$ designed the research. JHL and FP managed and followed up the patients. JHL collected the data and established the database. JHL and ZC presided over the enrollment and exclusion of the research subjects. JHL and XQX analyzed the data statistically. JHL drafted the manuscript. ZC participated in paper modification and revised the manuscript for English writing. All authors read and approved the final manuscript.

\section{Ethics approval and consent to participate}

The study was reviewed and approved by the ethic committee of the Second Xiangya Hospital, Central South University. The approval number was 2016-S022. All the participants provided informed written consents before their enrollment in the study. 


\section{Consent for publication}

Not applicable.

\section{Competing interests}

The authors declare that they have no competing interests.

\section{Publisher's Note}

Springer Nature remains neutral with regard to jurisdictional claims in published maps and institutional affiliations.

Received: 27 November 2018 Accepted: 15 April 2019 Published online: 30 April 2019

\section{References}

1. Moreau R, Jalan R, Gines P, Pavesi M, Angeli P, Cordoba J, , Durand F, Gustot T, Saliba F, Domenicali M, Gerbes A, Wendon J, Alessandria C, Laleman W, Zeuzem S, Trebicka J, Bernardi M, Arroyo V; CANONIC study investigators of the EASL-CLIF consortium. Acute-on-chronic liver failure is a distinct syndrome that develops in patients with acute decompensation of cirrhosis. Gastroenterology. 2013; 144(7):1426-1437.

2. Sarin SK, Kedarisetty CK, Abbas Z, Amarapurkar D, Bihari C, Chan AC, Chawla YK, Dokmeci AK, Garg H, Ghazinyan H, Hamid S, Kim DJ, Komolmit P, Lata S, Lee GH, Lesmana LA, Mahtab M, Maiwall R, Moreau R, Ning Q, Pamecha V, Payawal DA, Rastogi A, Rahman S, Rela M, Saraya A, Samuel D, Saraswat V, Shah S, Shiha G, Sharma BC, Sharma MK, Sharma K, Butt AS, Tan SS, Vashishtha C, Wani ZA, Yuen MF, Yokosuka O, Working Party APASLACLF. Acute-on-chronic liver failure: consensus recommendations of the Asian Pacific Association for the Study of the liver (APASL) 2014. Hepatol Int. 2014; 8(4):453-71

3. Li H, Chen LY, Zhang NN, Li ST, Zeng B, Pavesi M, Amorós À, Mookerjee RP, Xia Q, Xue F, Ma X, Hua J, Sheng L, Qiu DK, Xie Q, Foster GR, Dusheiko G, Moreau R, Gines P, Arroyo V, Jalan R. Characteristics, diagnosis and prognosis of acute-on-chronic liver failure in cirrhosis associated to hepatitis B. Sci Rep. 2016;6:25487.

4. Yin S, Wang SJ, Gu WY, Zhang Y, Chen LY, Li H. Risk of different precipitating events for progressing to acute-on-chronic liver failure in HBVrelated cirrhotic patients. J Dig Dis. 2017;18(5):292-301.

5. Shi Y, Yang $Y$, Hu Y, Wu W, Yang Q, Zheng $M$, Zhang $S, X u Z$, Wu Y, Yan $H$, Chen Z. Acute-on-chronic liver failure precipitated by hepatic injury is distinct from that precipitated by extrahepatic insults. Hepatology. 2015: 62(1):232-42.

6. Iloeje UH, Yang HI, Su J, Jen CL, You SL, Chen CJ. Risk evaluation of viral load elevation and associated liver disease/cancer-in HBV (the REVEAL-HBV) study group. Predicting cirrhosis risk based on the level of circulating hepatitis B viral load. Gastroenterology. 2006;130(3):678-86.

7. Lee MH, Yang HI, Liu J, Batrla-Utermann R, Jen CL, Iloeje UH, Lu SN, You SL, Wang LY, Chen CJ, R.E.V.E.A.L.-HBV Study Group. Prediction models of longterm cirrhosis and hepatocellular carcinoma risk in chronic hepatitis B patients: risk scores integrating host and virus profiles. Hepatology. 2013; 58(2):546-54.

8. Jeng WJ, Sheen IS, Liaw YF. Hepatitis B virus DNA level predicts hepatic decompensation in patients with acute exacerbation of chronic hepatitis B. Clin Gastroenterol Hepatol. 2010;8(6):541-5.

9. Lok AS, McMahon BJ, Brown RS Jr, Wong JB, Ahmed AT, Farah W, Almasri J, Alahdab F, Benkhadra K, Mouchli MA, Singh S, Mohamed EA, Abu Dabrh AM, Prokop LJ, Wang Z, Murad MH, Mohammed K. Antiviral therapy for chronic hepatitis $B$ virus infection in adults: a systematic review and metaanalysis. Hepatology. 2016;63(1):284-306.

10. Peng CY, Chien RN, Liaw YF. Hepatitis B virus-related decompensated liver cirrhosis: benefits of antiviral therapy. J Hepatol. 2012;57(2):442-50.

11. Mori N, Suzuki F, Kawamura Y, Sezaki H, Hosaka T, Akuta N, Kobayashi M, Saito S, Suzuki Y, Arase Y, Ikeda K, Kobayashi M, Kumada H. Determinants of the clinical outcome of patients with severe acute exacerbation of chronic hepatitis B virus infection. J Gastroenterol. 2012;47(9):1022-9.

12. Terrault NA, Bzowej $\mathrm{NH}$, Chang KM, Hwang JP, Jonas MM, Murad MH. AASLD guidelines for treatment of chronic hepatitis B. Hepatology. 2016; 63(1):261-83.

13. European Association for the Study of the Liver. Electronic address: easloffice@easloffice.eu., Lampertico P, Agarwal K, Berg T, Buti M, Janssen HLA, Papatheodoridis G, Zoulim F, Tacke F. EASL 2017 clinical practice guidelines on the management of hepatitis B virus infection. J Hepatol 2017: 67(2):370-398.

14. Sarin SK, Kumar M, Lau GK, Abbas Z, Chan HL, Chen CJ, Chen DS, Chen HL, Chen PJ, Chien RN, Dokmeci AK, Gane E, Hou JL, Jafri W, Jia J, Kim JH, Lai CL, Lee HC, Lim SG, Liu CJ, Locarnini S, Al Mahtab M, Mohamed R, Omata M, Park J, Piratvisuth T, Sharma BC, Sollano J, Wang FS, Wei L, Yuen MF, Zheng SS, Kao JH. Asian-Pacific clinical practice guidelines on the management of hepatitis B: a 2015 update. Hepatol Int. 2016;10(1):1-98.

15. Chinese Society of Hepatology, Chinese Medical Association; Chinese Society of Infectious Diseases, Chinese Medical Association, Hou JL, Wei L. The guideline of prevention and treatment for chronic hepatitis B: a 2015 update. Zhonghua Gan Zang Bing Za Zhi. 2015;23(12):888-905.

16. Shiha G, Ibrahim A, Helmy A, Sarin SK, Omata M, Kumar A, Bernstien D, Maruyama H, Saraswat V, Chawla Y, Hamid S, Abbas Z, Bedossa P, Sakhuja P, Elmahatab M, Lim SG, Lesmana L, Sollano J, Jia JD, Abbas B, Omar A, Sharma B, Payawal D, Abdallah A, Serwah A, Hamed A, Elsayed A, AbdelMagsod A, Hassanein T, Ihab A, GHaziuan H, Zein N, Kumar M. AsianPacific Association for the Study of the liver (APASL) consensus guidelines on invasive and non-invasive assessment of hepatic fibrosis: a 2016 update. Hepatol Int. 2017;11(1):1-30.

17. Durand F, Valla D. Assessment of the prognosis of cirrhosis: child-Pugh versus MELD. J Hepatol. 2005:42(S1):S100-7.

18. Castera L, Forns $X$, Alberti A. Non-invasive evaluation of liver fibrosis using transient elastography. J Hepatol. 2008;48(5):835-47.

19. Jia J, Hou J, Ding H, Chen G, Xie Q, Wang Y, Zeng M, Zhao J, Wang T, Hu X, Schuppan D. Transient elastography compared to serum markers to predict liver fibrosis in a cohort of Chinese patients with chronic hepatitis B. J Gastroenterol Hepatol. 2015;30(4):756-62.

20. Blei AT, Cordoba J. Practice parameters Committee of the American College of Gollege of gastroenterology. Hepatic Encephalopathy Am J Gastroenterol. 2001;96(7):1968-76.

21. European Association for the Study of the Liver. EASL clinical practice guidelines on the management of ascites, spontaneous bacterial peritonitis, and hepatorenal syndrome in cirrhosis. J Hepatol. 2010;53(3):397-417.

22. Gustot T, Durand F, Lebrec D, Vincent JL, Moreau R. Severe sepsis in cirrhosis. Hepatology. 2009;50(6):2022-33.

23. Kamath PS, Wiesner RH, Malinchoc M, Kremers W, Therneau TM, Kosberg CL, D'Amico G, Dickson ER, Kim WR. A model to predict survival in patients with end-stage liver disease. Hepatology. 2001;33(2):464-70.

24. Liver Failure and Artificial Liver Group. Chinese Society of Infectious Diseases, Chinese Medical Association; severe liver disease and artificial liver group, Chinese Society of Hepatology, Chinese Medical Association. Diagnostic and treatment guidelines for liver failure (2012 version). Zhonghua Gan Zang Bing Za Zhi. 2013;21(3):177-83.

25. Wang SJ, Yin S, Gu WY, Zhang Y, Li H. Acute-on-chronic liver failure exists in patients with hepatitis B virus-related decompensated cirrhosis. J Dig Dis. 2018;19(10):614-625.

26. Li N, Huang C, Yu KK, Lu Q, Shi GF, Zheng JM. Validation of prognostic scores to predict short-term mortality in patients with HBV-related acute-onchronic liver failure: the CLIF-C OF is superior to MELD, CLIF SOFA, and CLIFC ACLF. Medicine (Baltimore). 2017;96(17):e6802.

27. Vincent $J$, Moreno R, Takala J, Willatts S, De Mendonca A, Bruining H, Reinhart CK, Suter PM, Thijs LG. The SOFA (Sepsis-related organ failure assessment) score to describe organ dysfunction/failure. On behalf of the Working group on Sepsis-related problems of the European Society of Intensive Care Medicine. Intensive Care Med. 1996;22(7):707-10.

28. Fu X, Tan D, Dou X, Chen J, Wu J. A multi-center clinical study comparing Sansure Magb and CAP/CTM HBV tests in the quantitative detection of HBV DNA. J Infect Dev Ctries. 2016;10(7):755-61.

29. Trebicka J. Predisposing factors in acute-on-chronic liver failure. Semin Liver Dis. 2016;36(2):167-73.

30. Clària J, Arroyo V, Moreau R. The acute-on-chronic liver failure syndrome, or when the innate immune system goes astray. J Immunol. 2016;197(10): 3755-61.

31. Chang TT, Liaw YF, Wu SS, Schiff E, Han KH, Lai CL, Safadi R, Lee SS, Halota W, Goodman Z, Chi YC, Zhang H, Hindes R, lloeje U, Beebe S, Kreter B. Long-term entecavir therapy results in the reversal of fibrosis/cirrhosis and continued histological improvement in patients with chronic hepatitis B. Hepatology. 2010;52(3):886-93. 